\title{
Microangiopathy in human diabetic neuropathy: relationship between capillary abnormalities and the severity of neuropathy
}

\author{
R.A.Malik ${ }^{1}$, P.G. Newrick ${ }^{2}$, A.K.Sharma ${ }^{1}$, A.Jennings ${ }^{2}$, A. K. Ah-See ${ }^{1}$, T. M. Mayhew ${ }^{1}$, J.Jakubowski ${ }^{2}$, \\ A.J. M. Boulton ${ }^{3}$ and J.D. Ward ${ }^{2}$ \\ ${ }^{1}$ Departments of Anatomy and Surgery, University of Aberdeen, ${ }^{2}$ Diabetes Unit, Royal Hallamshire Hospital, Sheffield, and \\ ${ }^{3}$ Department of Medicine, Manchester Royal Infirmary, Manchester, UK
}

Summary. Clinical, electrophysiological and ultrastructural morphometric observations were made in 5 diabetic nonneuropathic patients, 5 diabetic patients with mild neuropathy and 11 diabetic patients with severe neuropathy. Capillary abnormalities were assessed in simultaneous nerve, muscle and skin biopsies and compared with results from 6 age-matched, non-diabetic control subjects.

Nerve capillaries demonstrated markedly greater pathology than skin and muscle capillaries. Endoneurial capillary density was significantly reduced in severely neuropathic diabetic patients $(p<0.01)$ when compared with control subjects. Capillary basement membrane $(p<0.002)$, endothelial cell $(p<0.003)$ and total diffusion barrier (endothelial cell, pericyte, basement membrane) $(p<0.001)$ thickness were significantly increased, and oxygen diffusing capacity was significantly reduced $(p<0.001)$ in the nerves of patients with severe diabetic neuropathy when compared to control subjects. Endothelial cell profile number and luminal perimeter were significantly increased in asymptomatic $(p<0.01)$, $(p<0.05)$ and severely neuropathic $(p<0.001),(p<0.05)$ diabetic patients respectively. However, endothelial cell outer perimeter, a measure of capillary size, showed no significant increase in diabetic patients when compared with control subjects. An association was observed between neurophysiological and neuropathological measures of neuropathic severity. There was no significant correlation between the duration of diabetes and $\mathrm{HbA}_{1}$ levels with capillary pathology or with neuropathic severity. Very few abnormalities of muscle and skin correlated with neuropathic severity. However, all measures of nerve capillary pathology correlated significantly with neurophysiological and neuropathological measures of neuropathic severity.

Key words: Diabetes, neuropathy, microangiopathy, heterogeneity, morphometry.
Diabetic neuropathy is one of the major complications of diabetes affecting both peripheral and autonomic nervous systems [1] with a prevalence rate of approximately $10 \%$ using strict clinical and electrophysiological criteria [2]. To date, the cause of diabetic neuropathy remains unresolved. There is a substantial body of evidence implicating metabolic dysfunction through disorders of the polyol and myo-inositol pathways [3].

Endoneurial microangiopathy and subsequent hypoxia have also been implicated in the development of diabetic neuropathy $[4,5]$. Recent studies have shown endoneurial capillary closure [6] and multifocal fibre loss in a pattern compatible with ischaemia [7, 8] in patients with diabetic neuropathy. Endoneurial hypoxia has been demonstrated in the sural nerve of diabetic patients with neuropathy [9] and diabetic animals [10]. Moreover, hypoxia due to chronic obstruc- tive airways disease has recently been shown to cause clinical, neurophysiological $[11,12]$ and pathological [13] abnormalities very similar to those observed in human diabetic neuropathy. Ischaemia and hypoxia in the human diabetic nerve may thus be due, at least partly, to microangiopathy, i.e. endoneurial capillary disease. It is not clear whether these intraneural abnormalities are merely a manifestation of generalised diabetic microangiopathy or are different from small vessel disease present elsewhere. The aim of this study, therefore, was to compare nerve capillary abnormalities with those in simultaneous muscle and skin biopsies. We have examined the relationship between the duration of diabetes and $\mathrm{HbA}_{1}$ levels with measures of microangiopathy and neuropathic severity and also the relationship between microangiopathy and neuropathic severity. 


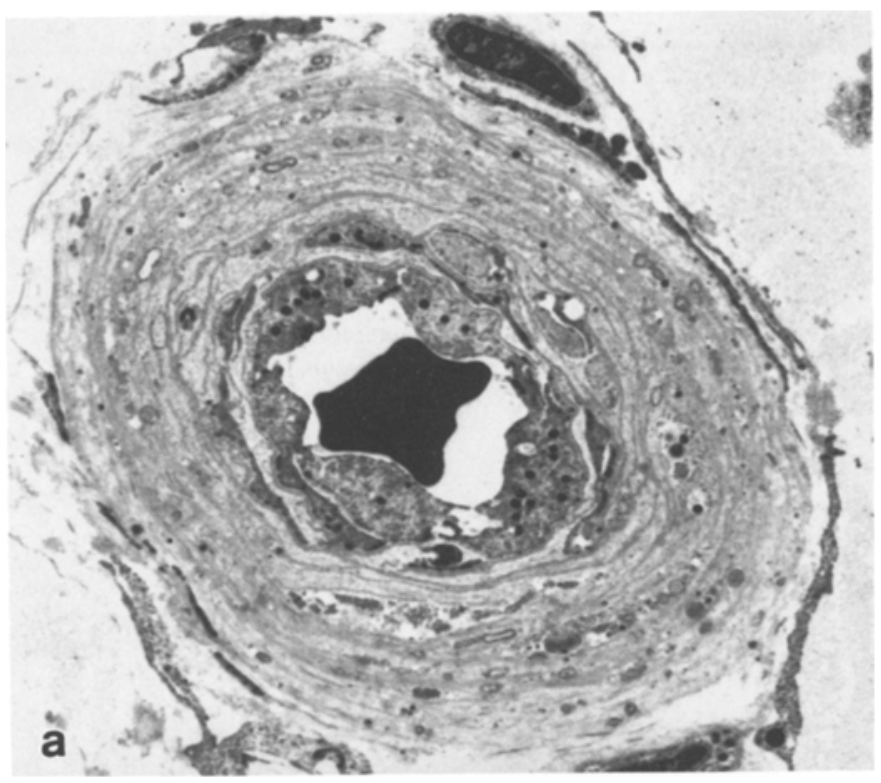

Fig. 1. Electron micrograph of endoneurial capillary from sural nerve of patient with severe diabetic neuropathy (a) with an outline (b) of the capillary structure showing $A=$ luminal aspect of endothelium; $\mathrm{B}=$ outer aspect of endothelium; $\mathrm{C}=$ outer aspect of basement membrane; $\mathrm{D}=$ endothelial cell thickness; $\mathrm{E}=$ basement membrane thickness; $\mathrm{F}=$ total diffusion barrier thickness

\section{Subjects and methods}

\section{Clinical assessment and electrophysiology}

Twenty-one diabetic patients and 6 control subjects were studied. The clinical characteristics of the diabetic patients are given in Table 1. Diabetic patients underwent history and full neurological examination. Assessment is as follows: (1) Ankle pressure index using a Doppler ultrasound stethoscope; (2) Warm thermal discrimination threshold measurement on the dorsum of the foot with a thermo-aesthesiometer (VU Hospital, Amsterdam, The Netherlands) using a forced choice method [2]; (3) Vibration perception threshold with a biothesiometer (Bio-Medical Instruments, Newbury, Ohio, USA); (4) Median and peroneal motor nerve conduction velocities with a Medelec DF06 electrophysiological system in a room at $25^{\circ} \mathrm{C}$. Patients were subsequently divided at random into three major groups by two observers basing their assessment on clinical symptoms and physical signs and the degree of abnormality in the functional tests. These groups consisted of: (1) diabetic non-neuropathic patients when all clinical and neurophysiological tests were normal; (2) mildly neuropathic (both median and peroneal motor nerve conduction velocities in the normal range and only one abnormal sensory threshold); and (3) severely neuropathic patients (sensory thresholds and nerve conduction velocities abnormal).

\section{Tissue biopsy}

This study was approved by the Physicians Advisory Ethical Committee and informed consent to perform open biopsies was obtained from all diabetic patients. Pre-operative $\mathrm{HbA}_{1}$ levels were assessed using previously described methods [14]. Volunteers from each of the groups with an ankle pressure index of greater than 1.0 (to exclude significant peripheral vascular disease) then underwent measurement of

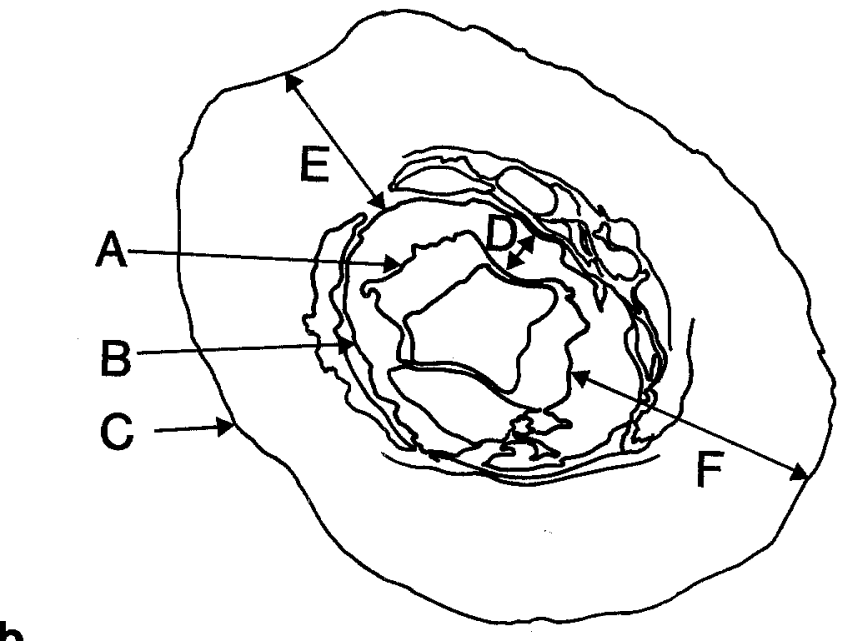

the sural nerve oxygen tension at the ankle [9]. Sural nerve biopsies posterior to the lateral malleolus were obtained under local $2 \%$ lignocaine anaesthesia. Only fascicular biopsies were taken from the diabetic non-neuropathic patients. Simultaneous biopsies of the vastus lateralis muscle and overlying skin were also obtained under local anaesthesia. Non-diabetic control sural nerve, muscle and skin biopsies were obtained from brain-dead transplant donors and traumatic amputees in whom neurophysiological and other investigations were not feasible at the time of biopsy.

Biopsies were fixed, processed, sectioned and examined according to previously described electron microscopic techniques [15]. All microvessels without a complete layer of cells (pericyte or smooth muscle cells) surrounding the endothelial cells were considered to be capillaries and were photographed at a final magnification of (X10,000-20,000). Light microscopic montages of all fasicles were prepared, and a direct estimation of myelinated fibre density was derived.

\section{Morphometric procedures}

Programmed digitisation (Commodore PET and BBC microcomputer systems) with a digitiser cursor linked to both a magneto-strictive and sonic digitiser (PMS Instruments Ltd., Maidenhead, Berks, U.K.) was employed. Mean fascicular area and endoneurial capillary density were assessed directly from the semi-thin sections using a camera lucida (Nachet, Evry, Franc_), sonic digitiser and video scan. The endothelial cell, basement membrane and total diffusion barrier harmonic mean thickness were assessed using the magneto-strictive digitiser. The luminal, endothelial cell outer and vessel perimeters were assessed using the sonic digitiser (Fig.1). The number of endothelial cell nuclei, pericyte nuclei and endothelial cell profiles (equivalent to the number of intercellular junctions) were counted directly from the electron micrographs.

\section{Rationale for morphometric procedures}

A transparent acetate overlay bearing parallel and equidistant test lines $1 \mathrm{~cm}$ apart was superimposed on each electronmicrograph in turn, so as to be random and independent in position and orientation [16]. Points of intersection between test lines and the outer aspects of the capillary basement membrane provided starting points for measuring random intercept lengths. Tangents were drawn through intersection points and orthogonals drawn from the points to the 
Table 1. Clinical details of diabetic patients studied

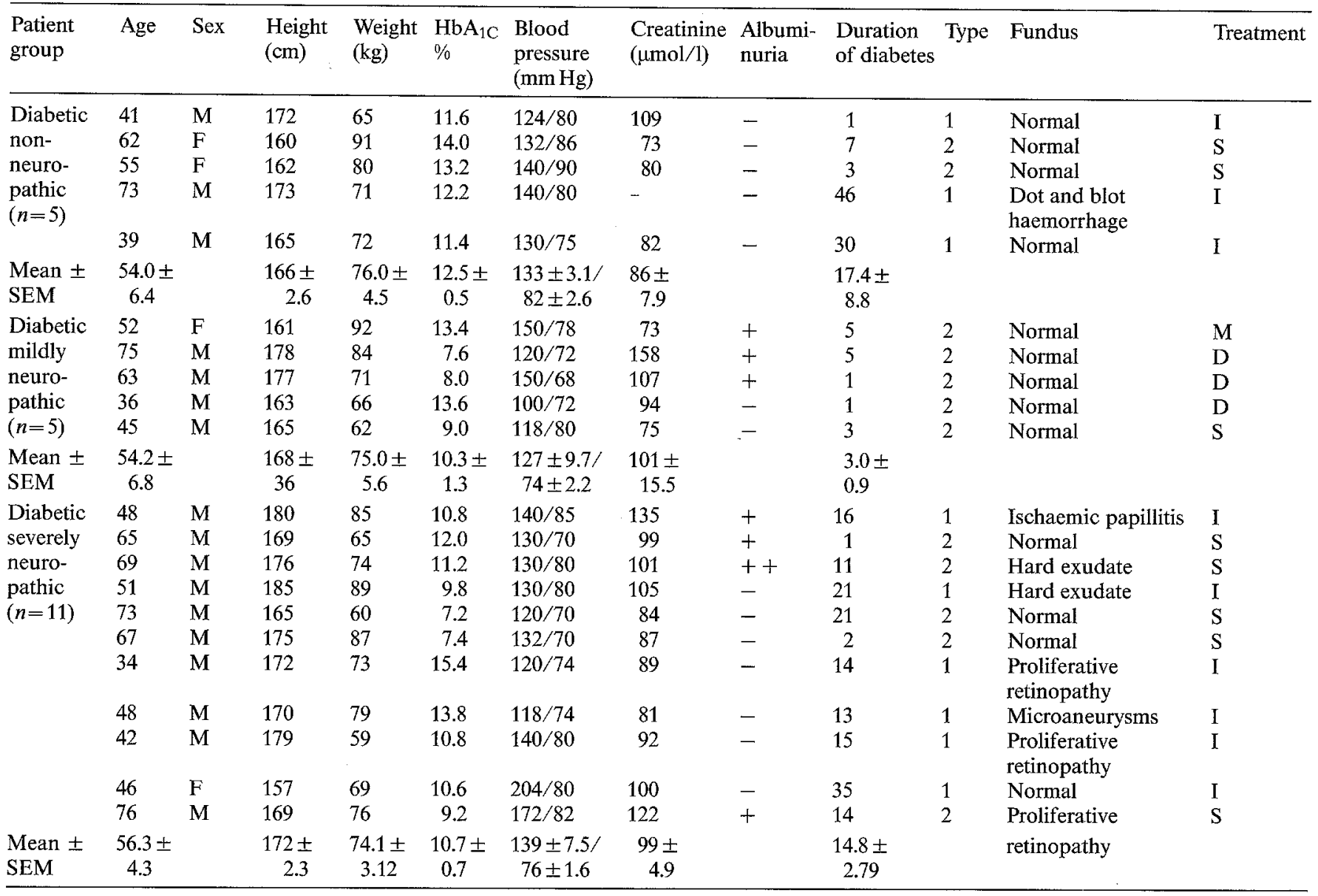

$n=$ number of patients studied; $\mathrm{I}=$ Insulin; $\mathrm{S}=$ Sulphonylurea; $\mathrm{M}=$ Metformin; $\mathrm{D}=$ Diet

luminal aspect of each capillary. All such distances (radial intercept lengths) were then measured using a magneto-strictive digitiser interfaced to a BBC microcomputer. The harmonic mean intercept length provides an estimate of harmonic mean thickness which gives greater weight to thinner areas of membrane, i.e. to precisely those areas where passive diffusion proceeds most effectively.

The oxygen diffusing capacity provides an expression of a physiological parameter derived from a combination of a large number of structural parameters. In order to estimate an oxygen diffusing capacity for the endoneurial capillary wall, a morphometric model based on Fick's gas diffusion equation was employed. This model provides an estimate of specific diffusing capacity $\mathrm{D}$ (cap), in $\mathrm{m} 10_{2}$ per $\mathrm{min} \cdot$ Torr $^{-1} \cdot \mathrm{ml}^{-1}$ tissue. The basic equation has the form:

$\mathrm{D}(\mathrm{cap})=\frac{(\mathrm{S}(\mathrm{o}) / \mathrm{V})+(\mathrm{S}(\mathrm{i}) / \mathrm{V})}{2 \mathrm{Th}} \times \mathrm{K}$

where $S(0) / V$ represents the surface density of the outer aspect of the diffusion barrier and $S(i) / V$ the surface density of the inner aspect of the diffusion barrier. Both densities have dimensions $\mathrm{cm}^{2} / \mathrm{ml}$ tissue. Th is the harmonic mean thickness of the barrier (in $\mathrm{cm}$ ) and $\mathrm{K}$ is Krogh's diffusion constant, taken to be $3 \times 10^{-8} \mathrm{~cm}$ per min. Torr ${ }^{-1}$ $[17,18]$. Both surface densities were estimated as the product of a perimeter length and a capillary packing density. For example, if $\mathrm{P}(\mathrm{o})$ denotes the mean perimeter length of the outer aspect of the barrier, in $\mathrm{cm}$, and $\mathrm{N}$ (cap) the number of capillaries per $\mathrm{cm}^{2}$ of nerve trunk, then the product $\mathrm{P}(\mathrm{o}) \cdot \mathrm{N}(\mathrm{cap})$ represents capillary perimeter length density in $\mathrm{cm} / \mathrm{cm}^{2}$ of nerve trunk. When both the nerve trunk and its capillaries are cylinders sectioned transversely, this quantity is a direct estimator of surface density in $\mathrm{cm}^{2}$ per $\mathrm{ml}$.

\section{Statistical analysis}

Spearman's rank correlation coefficients were calculated using the University of Aberdeen Honeywell-Bull DPS8/70 mainframe computer and Minitab statistical package. Differences between groups were tested using the two-tailed Mann-Whitney U test. For the purpose of analysis a vibration perception threshold of greater than 50 volts was assigned a value of 51 volts, and warm thermal discrimination threshold of greater than $20^{\circ} \mathrm{C}$ a value of $21^{\circ} \mathrm{C}$. Unrecordable nerve conduction velocities were assigned a value $1 \mathrm{~m} / \mathrm{s}$ lower than the lowest recorded measurement.

\section{Results}

\section{Clinical status}

Clinical characteristics of the diabetic patients are presented in Table 1. Age did not differ significantly between any of the groups of patients studied. The duration of diabetes was significantly greater in severely neuropathic patients when compared with mildly neuropathic patients $(p<0.02)$, but was not different from non-neuropathic diabetic patients. No significant difference was observed in the height, weight, $\mathrm{HbA}_{1}$, blood pressure and creatinine levels of the different groups of 
Table 2. Neurophysiological and morphological details of neuropathic severity in non-neuropathic (B), mildly neuropathic (C), severely neuropathic (D) diabetic patients (mean \pm SEM) and normal lower limits in control subjects (A). (NS - not significant)

\begin{tabular}{|c|c|c|c|c|c|c|c|}
\hline & A & B & $\mathrm{C}$ & D & $\mathrm{B}$ vs $\mathrm{C}$ & B vs $D$ & C vs D \\
\hline Age (years) & $57 \pm 9$ & $54 \pm 6$ & $54 \pm 6$ & $56 \pm 4$ & NS & NS & NS \\
\hline $\begin{array}{l}\text { Peroneal motor } \\
\text { nerve conduction } \\
\text { velocity }\left(\mathrm{ms}^{-1}\right)\end{array}$ & $>40$ & $43.8 \pm 2.2$ & $39.3 \pm 2.2$ & $28.9 \pm 2.7$ & NS & $p<0.005$ & $p<0.01$ \\
\hline $\begin{array}{l}\text { Median motor } \\
\text { nerve conduction } \\
\text { velocity }\left(\mathrm{ms}^{-1}\right)\end{array}$ & $>48$ & $52.5 \pm 2.4$ & $49.2 \pm 2.2$ & $42.3 \pm 8.8$ & NS & $p<0.05$ & NS \\
\hline $\begin{array}{l}\text { Vibration } \\
\text { perception } \\
\text { threshold (volts) }\end{array}$ & $<20$ & $12.2 \pm 3.4$ & $15.2 \pm 2.6$ & $32.3 \pm 3.6$ & NS & $p<0.008$ & $p<0.01$ \\
\hline $\begin{array}{l}\text { Thermal } \\
\text { discrimination } \\
\text { threshold }\left({ }^{\circ} \mathrm{C}\right)\end{array}$ & $<2.5$ & $1.8 \pm 0.9$ & $2.2 \pm 0.5$ & $23.6 \pm 2.8$ & NS & $p<0.002$ & $p<0.002$ \\
\hline $\begin{array}{l}\text { Myelinated } \\
\text { fibre density } \\
\left(\text { no } \cdot \mathrm{mm}^{-2}\right) \times 10^{3}\end{array}$ & $6.5 \pm 0.5$ & $5.6 \pm 0.4$ & $5.6 \pm 0.8$ & $1.7 \pm 0.3$ & NS & $p<0.002$ & $p<0.002$ \\
\hline
\end{tabular}

Table 3. Correlation between measures of neuropathic severity expressed as the Spearman's rank correlation coefficient $(r)$ and degree of significance

\begin{tabular}{llll}
\hline & $\begin{array}{l}\text { Vibration } \\
\text { perception } \\
\text { threshold } \\
\text { (volts) }\end{array}$ & $\begin{array}{l}\text { Thermal } \\
\text { discrimina- } \\
\text { tion threshold } \\
\left({ }^{\circ} \mathrm{C}\right)\end{array}$ & $\begin{array}{l}\text { Myelinated } \\
\text { fibre } \\
\text { density } \\
\left(\text { no } \cdot \mathrm{mm}^{-2}\right) \times 10^{3}\end{array}$ \\
\hline $\begin{array}{l}\text { Peroneal motor } \\
\text { nerve conduction } \\
\left.\text { velocity (ms }{ }^{-1}\right)\end{array}$ & $\begin{array}{l}r=-0.72 \\
p<0.001\end{array}$ & $\begin{array}{l}r=-0.87 \\
p<0.001\end{array}$ & $\begin{array}{l}r=0.71 \\
p<0.001\end{array}$ \\
$\begin{array}{l}\text { Vibration } \\
\text { perception } \\
\text { threshold (volts) }\end{array}$ & & $r=0.76$ & $\begin{array}{l}r=-0.74 \\
p<0.001\end{array}$ \\
$\begin{array}{l}\text { Thermal } \\
\text { discrimination } \\
\text { threshold }\left({ }^{\circ} \mathrm{C}\right)\end{array}$ & & $p<0.001$ & $\begin{array}{l}r=-0.78 \\
p<0.001\end{array}$ \\
\hline
\end{tabular}

diabetic patients studied. Other complications in diabetic patients were albuminuria $(1+n=6,2+n=1)$ and retinopathy (background $n=5$, inactive proliferative $n=3$ ).

\section{Neurophysiological and neuropathological measures of neuropathic severity}

Peroneal motor nerve conduction velocity was significantly reduced in severely neuropathic patients when compared with both mildly neuropathic $(p<0.01)$ and non-neuropathic $(p<0.005)$ diabetic patients. Median nerve conduction velocity was reduced in severely neuropathic patients only when compared with nonneuropathic diabetic patients $(p<0.05)$. With regard to sensory tests, vibration perception and thermal discrimination thresholds were significantly increased in severely neuropathic patients when compared with mildly neuropathic $(<0.01 ; p<0.002$ respectively) and non-neuropathic $(p<0.008 ; p<0.002$ respectively) diabetic patients. Myelinated fibre density was significantly reduced in severely neuropathic patients when compared with mild $(p<0.02)$ and non-neuropathic $(p<0.002)$ diabetic patients (Table 2). Moreover, significant associations were observed between peroneal nerve conduction velocity, vibration perception threshold, thermal discrimination threshold and myelinated fibre density (Table 3 ).

\section{Muscle capillaries}

Abnormalities of muscle capillaries in diabetic and non-diabetic patients studied are shown qualitatively (Fig. 2) and quantitatively in Table 4. Endothelial cell profile number/capillary was not significantly different between diabetic patients and control subjects; however, endothelial cell thickness was significantly increased only in mildly neuropathic patients when compared with non-diabetic control subjects $(p<0.02)$. With regard to the capillary wall, basement membrane thickness was significantly increased only in severely neuropathic patients $(p<0.01)$ whereas the total diffusion barrier thickness was significantly increased in both mildly neuropathic $(p<0.02)$ and severely neuropathic $(p<0.05)$ diabetic patients when compared with non-diabetic control subjects.

\section{Skin capillaries}

Anormalities of skin capillaries in diabetic patients and control subjects are shown qualitatively in Figure 3 and quantitatively in Table 4. No significant difference was observed in endothelial cell profile number, endothelial cell thickness and total diffusion barrier thickness between any group of patients studied (Table 4). How- 

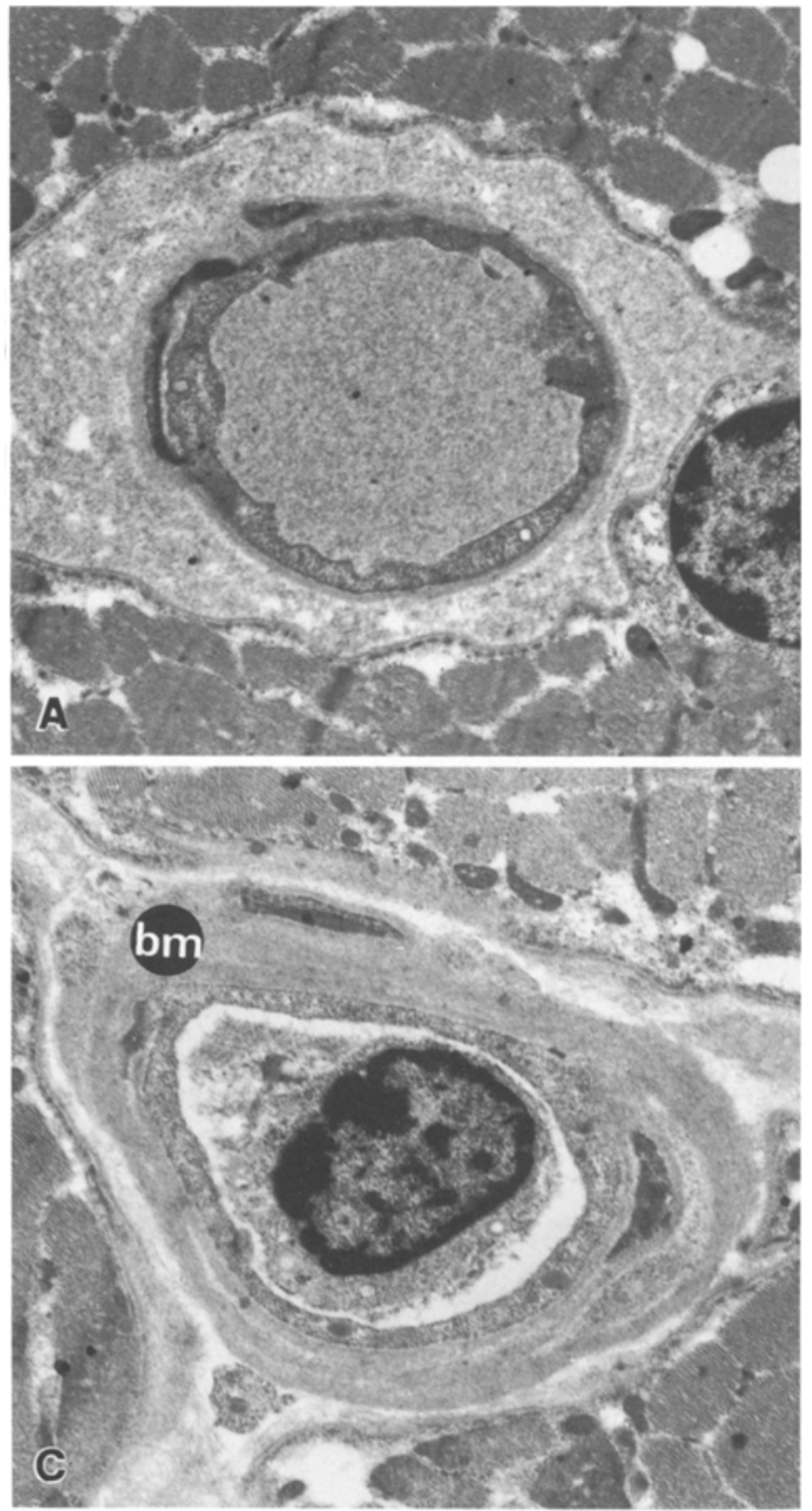

Fig. 2. Electron micrographs of capillaries from skeletal muscle of a control subject (A), diabetic mildly neuropathic patient $(\mathbf{B})$ and diabetic severely neuropathic patient (C) showing progressive thickening of basement membrane (bm). $(\times 12100)$

ever, basement membrane thickness was significantly increased in severely neuropathic patients when compared with mildly neuropathic diabetic patients $(p<0.05)$ and non-diabetic control subjects $(p<0.01)$.

\section{Endoneurial capillaries}

Endoneurial capillaries were markedly abnormal and the results are shown qualitatively in Fig. 4 and quantitatively in Table 5 . Endothelial cell profile number was increased in severely neuropathic $(p<0.001)$ and nonneuropathic diabetic patients $(p<0.01)$; and endothelial cell nuclear number was also significantly increased in severely neuropathic patients $(p<0.01)$ when com-

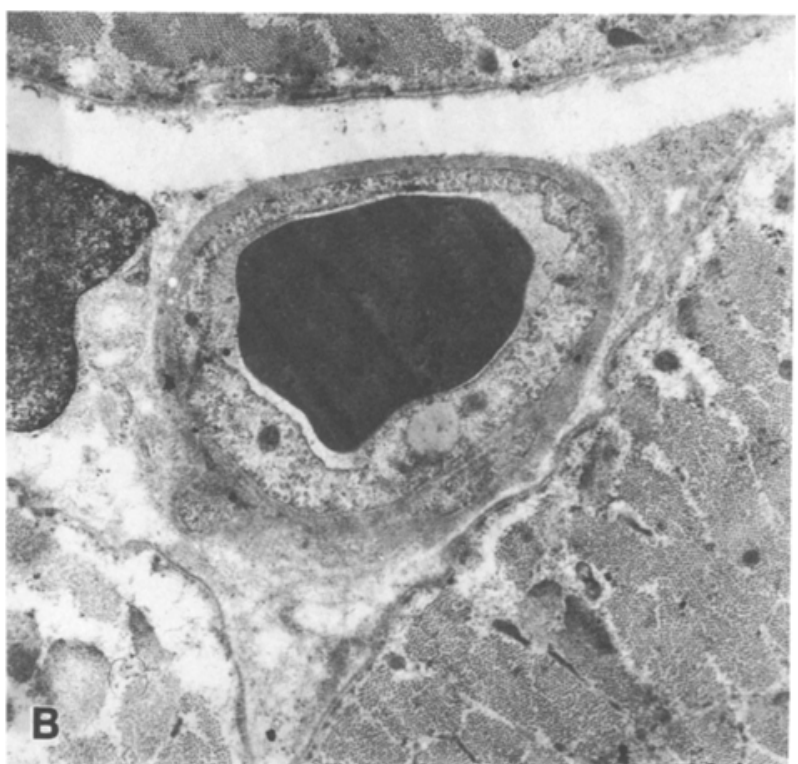

pared with non-diabetic control subjects indicative of endothelial cell hyperplasia. Endothelial cell hypertrophy was demonstrated in the form of increased endothelial cell thickness in severely neuropathic patients $(p<0.003)$ as compared with non-diabetic control subjects. Basement membrane thickness was significantly increased in both severely neuropathic $(p<0.002)$ and mildly neuropathic $(p<0.05)$ patients when compared with control subjects, clearly increasing with neuropathic severity. The total diffusion barrier thickness was significantly greater in severely neuropathic $(p<0.05)$ and non-neuropathic $(p<0.02)$ diabetic patients than in control subjects. The pericyte nuclear number was significantly increased in severely neuropathic diabetic patients $(p<0.01)$ when compared to control subjects; however, the endothelial/pericyte cell nuclear ratio remained unchanged in all groups of diabetic patients. With regard to capillary size and diffusing areas, the luminal perimeter was significantly greater in severely neuropathic $(p<0.05)$ and non-neuropathic $(p<0.05)$ diabetic patients than in control subjects. Importantly, the endothelial cell outer perimeter was not significantly increased in any of the groups of diabetic patients studied. Vessel perimeter was significantly increased in severely neuropathic $(p<0.002)$, mildly neuropathic $(p<0.02)$ and non-neuropathic $(p<0.01)$ diabetic patients when compared with control subjects.

Non-neuropathic patients demonstrated a non-significant decrease in the number of capillaries/fascicle and mildly and severely neuropathic diabetic patients exhibited a non-significant increase in the number of capillaries/fascicle as compared with control subjects. The mean fascicular area was significantly increased in both mildly neuropathic $(p<0.05)$ and severely neuropathic $(p<0.004)$ diabetic patients and capillary density was accordingly reduced in severely neuropathic patients $(p<0.01)$ when compared with control subjects. 
Table 4. Morphometric measurements of muscle and skin capillaries in non-diabetic control subjects (A), diabetic (mild neuropathy) patients (C) and diabetic (severe neuropathy) patients (D) presented as mean \pm SEM and degree of significant difference between groups (NS - not significant)

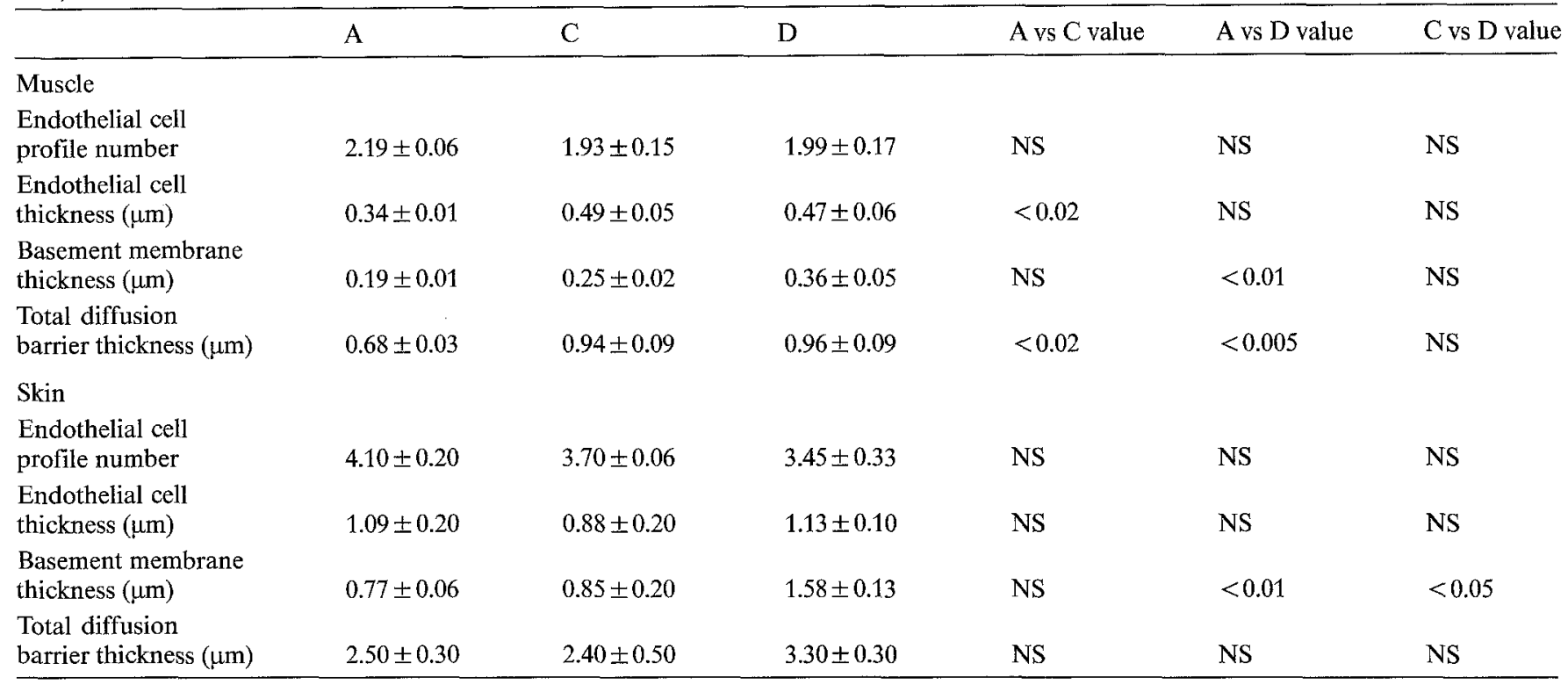

As a consequence of this array of endoneurial capillary abnormalities, the estimated capillary oxygen diffusing capacity was significantly reduced in the severely neuropathic diabetic patients $(p<0.001)$ when compared with control subjects

\section{Correlation between diabetic state, neuropathy and microangiopathy}

Duration of diabetes and $\mathrm{HbA}_{1}$ levels showed no significant association with measures of neuropathic severity. Also $\mathrm{HbA}_{1}$ levels did not correlate with any of the measures of nerve, muscle or skin capillary pathology. Furthermore, of all the measures of capillary pathology only endothelial cell thickness of nerve $(r=0.47 ; p<0.05)$ and muscle $(r=-0.4 ; p<0.05)$ capillaries correlated with the duration of diabetes.

\section{Correlation between microangiopathy and neuropathic severity}

The relationship between abnormalities of nerve, muscle and skin capillaries and measures of neuropathic severity is shown in Table 6. There was a weak association between muscle endothelial cell thickness and reduced nerve conduction $(r=0.56 ; p<0.01)$ and abnormal thermal discrimination $(r=0.51 ; p<0.02)$. Muscle capillary basement membrane thickening was also weakly associated with reduced myelinated fibre density $(r=-0.42 ; p<0.05)$. Skin basement membrane thickness was significantly associated with reduced nerve conduction $(r=-0.54 ; p<0.01)$ and abnormal thermal discrimination $(r=0.62 ; p<0.01)$. However, highly significant associations were demonstrated between measures of nerve capillary pathology, namely, endothelial cell profile number/capillary, endothelial cell thickness, basement membrane thickness, total diffusion barrier thickness, capillary oxygen diffusion capacity and both neurophysiological and neuropathological measures of neuropathic severity (Table 6).

\section{Discussion}

Both hypoxic [4, 5] and metabolic [3] factors have been implicated in the development of human diabetic neuropathy. Animal models have provided strong [3] but questionable [19] evidence for increased polyol levels, reduced myoinositol and reduced $\mathrm{Na}^{+} / \mathrm{K}^{+}$ ATPase activity with structural alterations of the node of Ranvier [20]. Evidence from studies of human nerve biochemistry, however, appears to be conflicting. Some studies have demonstrated elevated polyol levels [21-26] with a reduction in myoinositol levels [22]. Neurophysiological and morphological measures of neuropathic severity have recently shown a relationship with sorbitol elevation $[25,26]$. However, biopsy studies have revealed no reduction in nerve myoinositol [23-25] and also no significant relationship between nerve myoinositol and measures of neuropathic severity [25].

Alternatively, recent studies have provided an impressive body of evidence to implicate hypoxia in the development of reduced nerve conduction velocity and a resistance to ischaemia without biochemical perturbations in hypoxic animals [4] and hypoxic patients with chronic obstructive airways disease [11-13]. Patients 

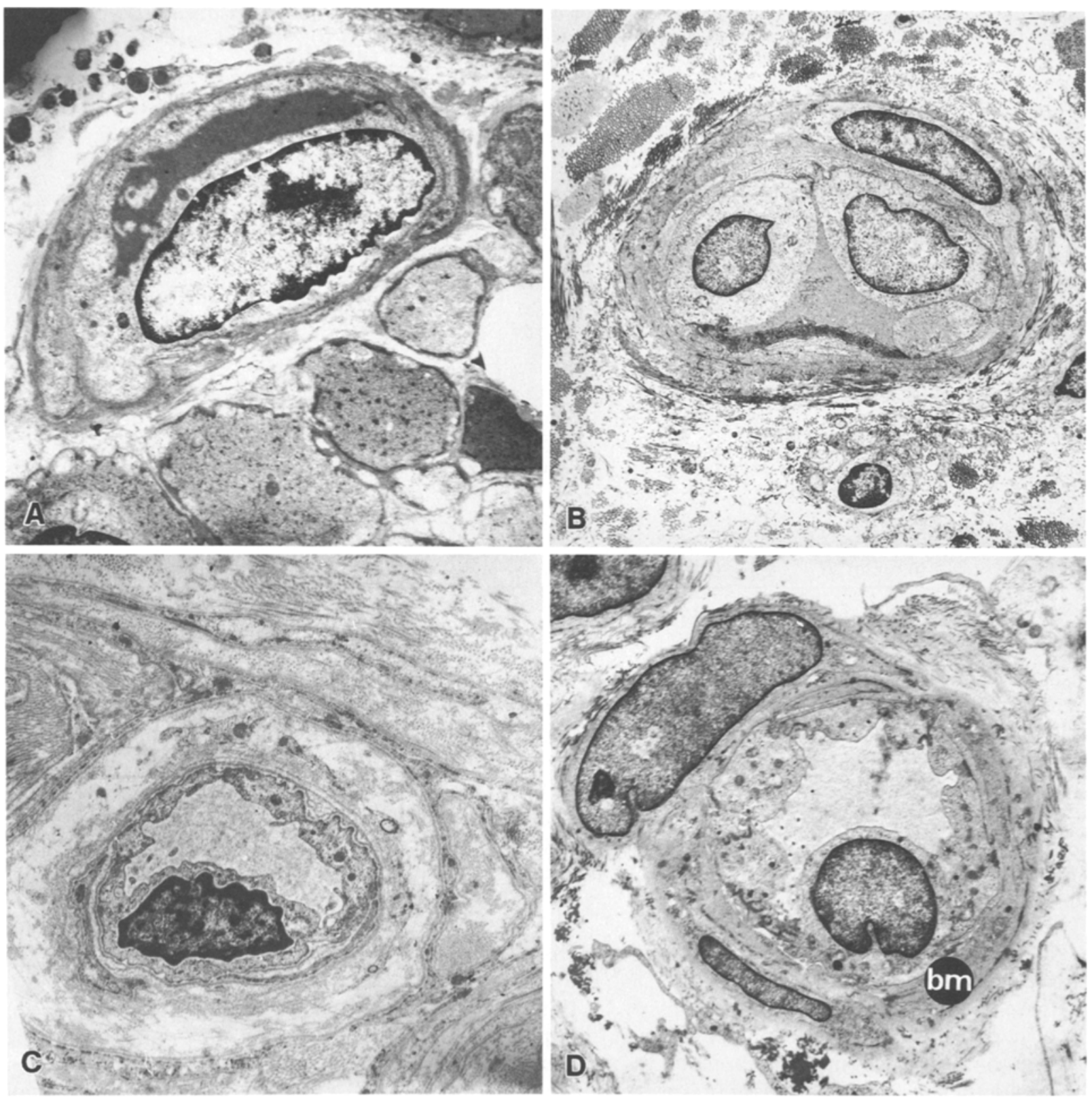

Fig.3. Electron micrographs of capillaries from skin of a control subjects (A), diabetic non-neuropathic patient (B), diabetic mildly neuropathic patient $(\mathbf{C})$ and diabetic severely neuropathic patient (D), showing reduplication of basement membrane $(\mathrm{bm}) .(\times 5600)$

with diabetic neuropathy have reduced sural nerve endoneurial oxygen tension [9]. Furthermore, the pattern of fibre loss in human diabetic neuropathy has been considered by some investigators to be ischaemic in origin [7,8], although this proposal has been challenged recently [27]. Thus microangiopathy, a hallmark of diabetes, may well, as originally proposed by Fagerberg [28], be responsible for the development of hypoxia and resultant neuropathy.

Pathologically, three major issues require resolution before implicating microvascular disease in the devel- opment of human diabetic neuropathy: (1) that endoneurial capillary disease is not simply a reflection of generalized diabetic microangiopathy; (2) that nerve microvascular disease has characteristic features potentially severe enough to create hypoxia and, thereby, nerve damage; (3) that nerve capillary pathology provides a good association with the neurophysiological and pathological measures of neuropathic severity, thereby strengthening the evidence for a cause/effect relationship.

With regard to microvascular pathology, we have demonstrated clear differences between nerve, muscle and skin capillary pathology. The basement membrane was thickened in nerve [29], muscle [30] and skin [31] capillaries of diabetic patients with severe neuropathy in agreement with other studies. However, because of our unique simultaneous muscle, skin and nerve biopsy 


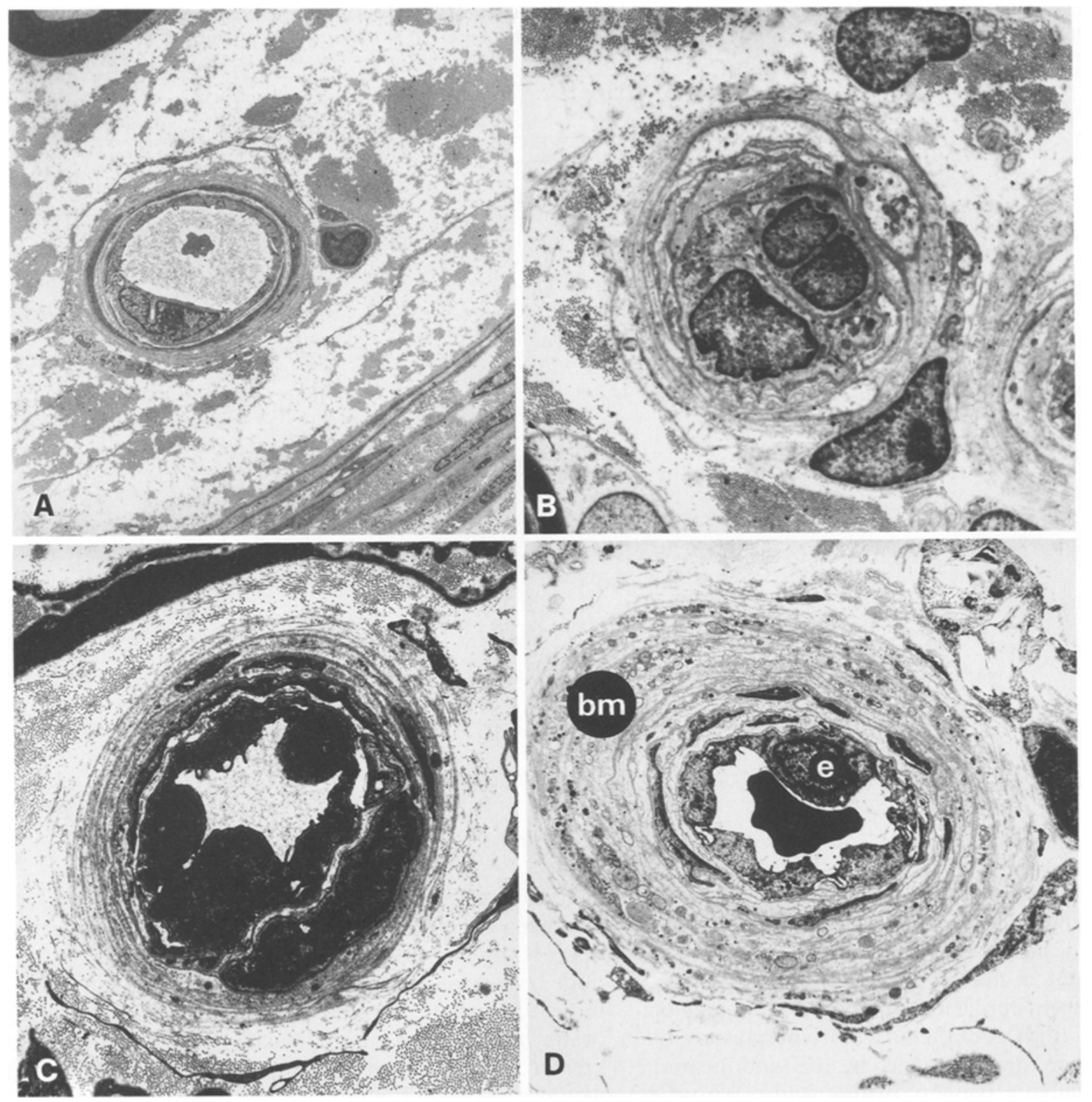

Fig.4. Electron micrographs of endoneurial capillaries from sural nerve of a control subject (A), diabetic non-neuropathic patient (B), diabetic mildly neuropathic patient $(C)$ and diabetic severely neuropathic patient (D) with progressive increase in endothelial cell (E) number and thickened reduplicated basement membrane (bm) $(\times 3000)$

procedure, we have shown that capillary basement membrane thickening is proportionately far greater in nerve than in skin which in turn is greater than in muscle from the same diabetic patients. As nerve is insulin-independent and muscle and skin are insulin-dependent, the glucose concentrations, the rate of nonenzymatic glycosylation [32] and the capillary basement membrane thickening would, therefore, be expected to be greater in nerve than in muscle or skin. Muscle and skin capillaries demonstrated neither endothelial cell hyperplasia nor hypertrophy and even exhibited a trend for reduction in cell number, indicative of cell death
[33]. However, endothelial cell hyperplasia and hypertrophy were marked early and late features of diabetic nerve capillaries in agreement with other studies $[6,29$, $34,35]$. This discrepancy suggests the need for caution when interpreting muscle and skin capillary biopsy data, particularly with regard to endothelial cell pathology and its relationship to diabetic neuropathy. An increase in the pericyte nuclear number of and unchanged pericyte/endothelial cell nuclear ratio was observed in the present study. These features of endoneurial capillary pathology are different from diabetic retinopathy [36] and muscle microangiopathy [33] where there is a loss of pericytes and an altered pericyte/endothelial cell ratio. It is, therefore, clear that diabetic endoneurial microangiopathy is not merely a reflection of generalised microangiopathy.

Features of endoneurial capillary microangiopathy capable of creating hypoxia were prominent. Fascicular expansion attributed to endoneurial oedema [37] 
Table 5. Morphometric measurements of endoneurial capillaries in non-diabetic control subjects (A), diabetic non-neuropathic patients (B), diabetic (mild neuropathy) patients $(C)$ and diabetic (severe neuropathy) patients (D) presented as mean \pm SEM and degree of significant difference between groups. (NS - not significant)

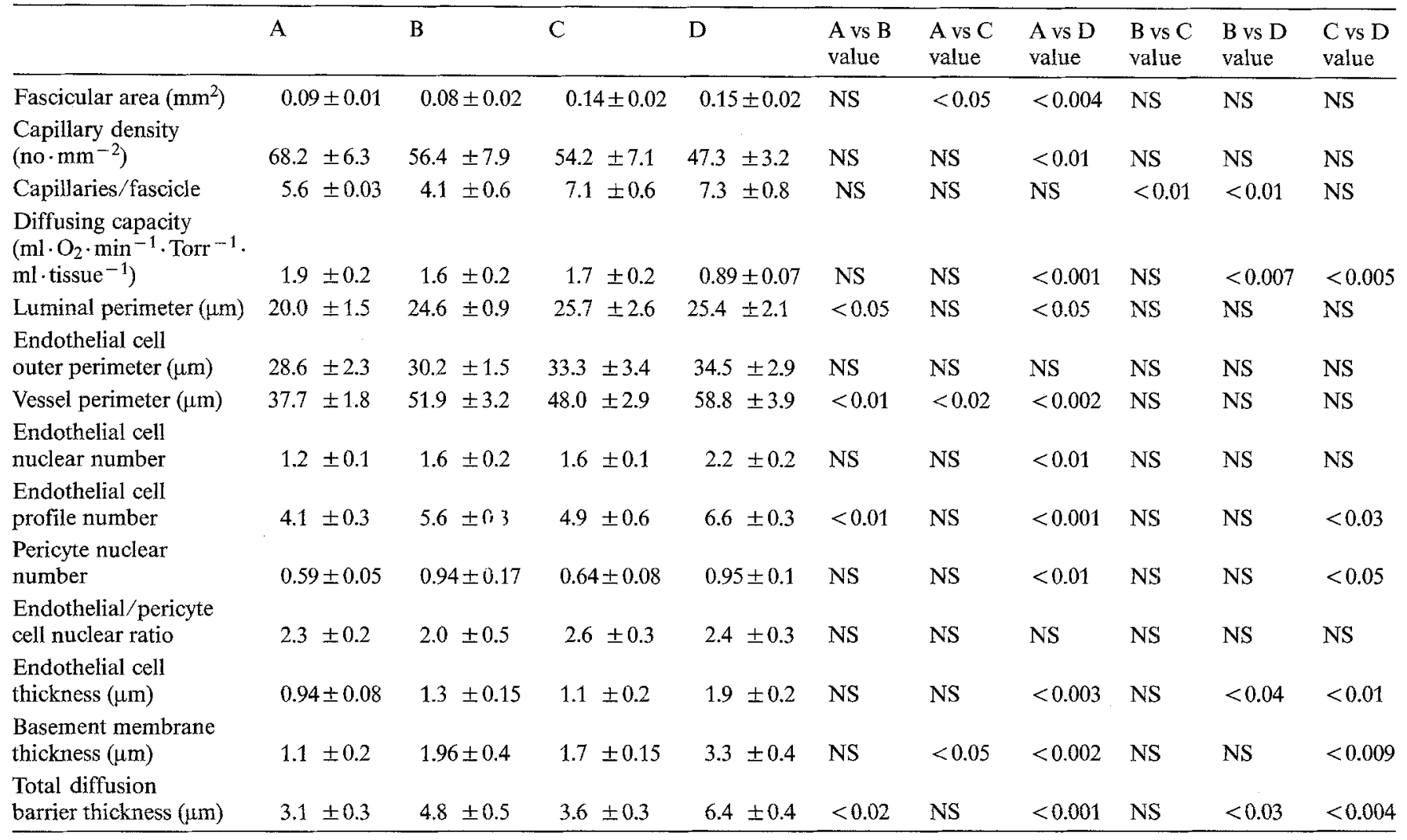

and fibrosis [38] was observed in both mildly and severely neuropathic patients sufficient to reduce capillary density and, hence, perfusion in the latter group. Capillary luminal occlusion will reduce nerve blood flow and has been implicated in the development of neuropathy [6]. Both endothelial cell hyperplasia and hypertrophy were demonstrated in the endoneurial capillaries of diabetic patients in this study. We propose that endothelial cell hyperplasia in conjunction with an increased luminal perimeter may represent an adaptive measure to increase the capillary luminal surface area and, thereby, enhance oxygen diffusion to the compromised hypoxic nerve [9]. It may also represent angiogenesis as endothelial cell proliferation is an essential prerequisite for new vessel formation [39]. The number of capillaries/fascicle was significantly increased in severely neuropathic diabetic patients when compared with non-neuropathic diabetic patients, indicative of angiogenesis. Paradoxically, however, capillary size based on the endothelial cell outer perimeter length was not increased. The basement membrane thickening around the endothelial cells may provide a barrier to prevent an increase in capillary size. Thus the proliferating hyperplastic cells must gradually encroach upon the limited free luminal space, thereby reducing blood flow and ultimately this will result in vessel closure [6]. Reduced microvascular blood flow
[40] and an impaired hyperaemic response [41] have also been observed in the skin of patients with diabetic neuropathy and are considered to be secondary to reduced vascular distensibility due to basement membrane deposition. As the degree of basement membrane and capillary wall thickening is several times greater in nerve than in skin, this mechanism alone would be expected to impair nerve capillary perfusion. Furthermore, extensive haematological and haemorrheological abnormalities, primarily in the form of reduced erythrocyte deformability, increased plasma viscosity and increased haemoglobin affinity for oxygen will also reduce nerve oxygenation [42].

This study has revealed a good correlation between neurophysiological and neuropathological measures of neuropathic severity in agreement with a recent study [43]. Furthermore, endoneurial capillary abnormalities demonstrated a very significant correlation with both neurophysiological and neuropathological measures of neuropathic severity. However, this study has shown no relationship between the duration of diabetes and $\mathrm{HbA}_{1}$ levels with measures of microangiopathy or neuropathy [25] suggesting that metabolic alterations do not bear a simple relationship with the development and progression of neuropathy or microangiopathy.

In conclusion, the present study has revealed more prominent microangiopathy in nerve, compared with 
Table 6. Correlations between capillary abnormalities in Nerve $(\mathrm{N})$, Muscle $(\mathrm{M})$ and Skin $(\mathrm{S})$ and measures of neuropathic severity expressed as the Spearman's rank correlation coefficient ( $r$ ) and degree of significance. (NS - not significant)

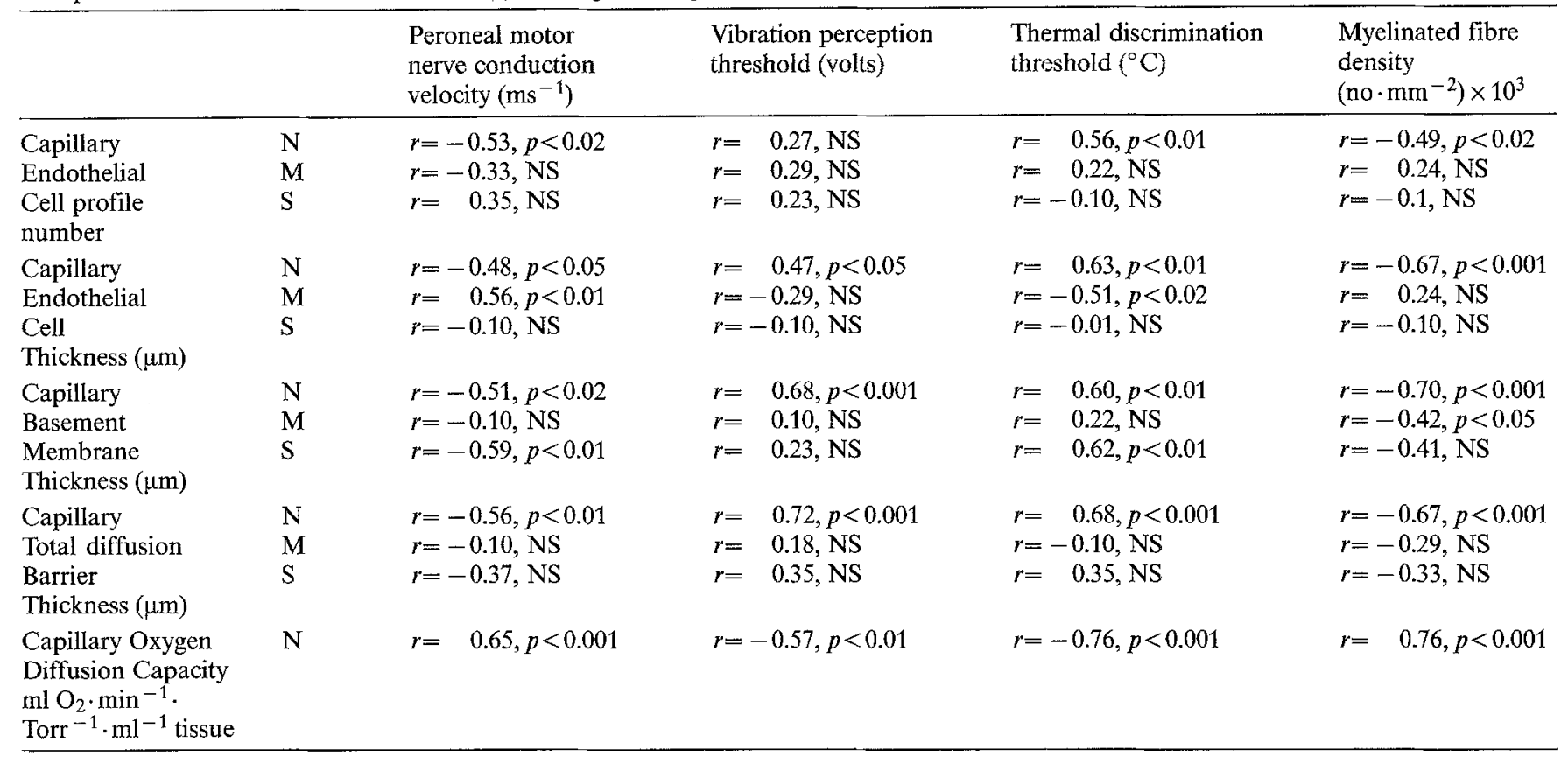

muscle and skin, from the same diabetic patients both with and without neuropathy. The features of endoneurial microangiopathy are consistent with proposed mechanisms considered to create endoneurial hypoxia. Furthermore, a highly significant correlation was demonstrated between nerve microangiopathy and measures of neuropathic severity. Muscle and skin capillaries failed to demonstrate such an association. This study, therefore, provides strong support for the concept that endoneurial capillary disease plays an important role in both the development and progression of human diabetic neuropathy.

Acknowledgements. Financial support from the British Diabetic Association is gratefully acknowledged. The authors are indebted to Dr. R. J. Young, Royal Infirmary of Edinburgh, Edinburgh, UK who provided some control nerve biopsies. We thank Dr. N.S. Fineberg, Diabetes Research and Training Center, Indiana University, Ind., USA, for statistical advice and Mrs. E. Kay, Mrs. M. Moir and Mrs. C.Maurer for typing the manuscript. Finally, we thank Professor E.J.Clegg, Department of Anatomy, University of Aberdeen, Aberdeen, UK for his support and encouragement of this work.

\section{References}

1. Thomas PK, Eliasson SG (1984) Diabetic neuropathy. In: Dyck PJ, Thomas PK, Lambert EH, Bunge R (eds) Peripheral neuropathy, 2nd edn. Saunders, Philadelphia, p 1773-1810

2. Newrick PG, Boulton AJM, Ward JD (1986) The distribution of diabetic neuropathy in a British clinic population. Diab Res Clin Pract 2: 263-268

3. Greene DA, Lattimer S, Ulbrecht J, Carroll P (1985) Glucose induced alterations in nerve metabolism. Current perspective on the pathogenesis of diabetic neuropathy and future directions for research and therapy. Diabetes Care 8: 290-299
4. Low PA, Tuck RR, Takeuchi M (1987) Nerve microenvironment in diabetic neuropathy. In: Dyck PJ, Thomas PK, Asbury AK, Winegrad AI, Porte D (eds) Diabetic neuropathy. Saunders, Philadelphia, p 266-278

5. Lagerlund TD, Low PA (1987) A mathematical simulation of oxygen delivery in rat peripheral nerve. Microvasc Res 34: 211-222

6. Dyck PJ, Hansen S, Karnes J, O'Brien P, Yasuda H, Windebank A, Zimmermann B (1985) Capillary number and percentage closed in human diabetic sural nerve. Proc Natl Acad Sci USA 82: 2513-2517

7. Dyck PJ, Karnes JL, O'Brien P (1986) The spatial distribution of fibre loss in diabetic polyneuropathy suggests ischaemia. Ann Neurol 19: 440-449

8. Johnson PC, Doll SC, Cromey DW (1986) Pathogenesis of diabetic neuropathy. Ann Neurol 19:450-457

9. Newrick PG, Wilson AJ, Jakubowski J, Boulton AJM, Ward JD (1986) Sural nerve oxygen tension in diabetes. Br Med J 293: 1053-1054

10. Tuck RR, Schmelzer JD, Low PA (1984) Endoneurial blood flow and oxygen tension in the sciatic nerves of rats with experimental diabetic neuropathy. Brain 107:935-950

11. Paramelle B, Vila A, Pollak P, Muller P, Gavelle O, Reymond F, Branbilla C, Stoebner P (1986) Frequence des polyneuropathies dans les bronchopneumopathies chroniques obstructives. Presse Med 12: 563-567

12. Masson EA, Church SE, Woodcock AA, Hanley SP, Boulton AJM (1988) Is resistance to ischaemic conduction failure induced by hypoxia? Diabetologia 31: 762-765

13. Boulton AJM, Masson EA, Malik RA, Sharma AK, Lye RH, Woodcock AA (1988) Chronic hypoxic neuropathy: a human model for diabetic neuropathy? Diabetes 37 [Suppl.1]: 338A

14. Fluckinger R, Winterhalter WM (1976) In vitro synthesis of haemoglobin Alc. FEBS Lett 71: 356-360

15. Archer AG, Watkins PJ, Thomas PK, Sharma AK, Payan J (1983) The natural history of acute painful neuropathy in diabetes mellitus. J Neurol Neurosurg Psychiatry 46: 491-499

16. Mayhew TM, Joy CF, Haas JD (1984) Structure function correlation in the human placenta: the morphometric diffusing capacity for oxygen at full term. J Anat 139:691-708 
17. Weibel ER (1970) Morphometric estimation of pulmonary diffusing capacity 1. Model and method. Respir Physiol 11: 54-75

18. Weibel ER (1984) Delivering oxygen to the cells. In: Weibel ER The pathway for oxygen. Harvard University Press, Cambridge, MA, pp 175-210

19. Lambourne JE, Brown AM, Calcutt N, Tomlinson DR, Willars GB (1988) Adenosine triphosphate in nerves and ganglia of rats with streptozotocin-induced diabetes or galactosemia; effects of aldose reductase inhibition. Diabetologia 31: 379-384

20. Greene DA, Chakrabarti S, Lattimer SA, Sima AAF (1987) Role of sorbitol accumulation and myo-inositol depletion in paranodal swelling of large myelinated nerve fibres in the insulin-deficient spontaneously diabetic bio-breeding rat. Reversal by insulin treatment, an aldose reductase inhibitor and myo-inositol. J Clin Invest 79: $1479-1485$

21. Ward JD, Baker RWR, Davis BH (1972) Effect of blood sugar control on the accumulation of sorbitol and fructose in nervous tissues. Diabetes 21: 1173-1178

22. Mayhew JA, Gillon KRW, Hawthorne JN (1983) Free and lipid inositol, sorbitol and sugars in sciatic nerve obtained post-mortem from diabetic patients and control subjects. Diabetologia 24: $13-15$

23. Hale PJ, Nattrass M, Silverman SH, Sennit C, Perkins CM, Uden A, Sundkvist G (1987) Peripheral nerve concentrations of glucose, fructose, sorbitol and myoinositol in diabetic and non-diabetic patients. Diabetologia 30: 464-467

24. Dyck PJ, Sherman WR, Hallcher LM, Service JF, O'Brien P, Grisa LS, Palumbo PJ, Swanson CJ (1980) Human diabetic endoneurial sorbitol, fructose and myoinositol related to sural nerve morphometry. Ann Neurol 8: 590-596

25. Dyck PJ, Zimmerman BR, Vilen TH, Minnerath SR, Karnes JL, Yao JK, Poduslo JF (1988) Nerve glucose, fructose, sorbitol, myoinositol, and fibre degeneration and regeneration in diabetic neuropathy. N Engl J Med 319: 542-548

26. Sima AAF, Bril V, Nathaniel V, McEwen TAJ, Brown MB, Lattimer SA, Greene DA (1988) Regeneration and repair of myelinated fibres in sural nerve biopsy specimens from patients with diabetic neuropathy treated with Sorbinil. N Engl J Med 319: 548-555

27. Llewellyn JG, Thomas PK, Gilbey SG, Watkins PJ, Muddle JR (1988) Pattern of myelinated fibre loss in the sural nerve in neuropathy related to type I (insulin dependent) diabetes. Diabetologia 31: 162-167

28. Fagerberg SE (1959) Diabetic neuropathy. A clinical and histological study on the significance of vascular affections. Acta Med Scand 164 [Suppl 345]: 1-109

29. Yasuda H, Dyck PJ (1987) Abnormalities of endoneurial microvessels and sural nerve pathology in diabetic neuropathy. Neurology $37: 20-28$

30. Sosenko JM, Miettinen OS, Williamson JR, Gabbay KH (1984)
Muscle capillary basement-membrane thickness and long term glycemia in type 1 diabetes mellitus. N Engl J Med 311: 694-698

31. Friederici AHR, Tucker WR, Schwartz TB (1966) Observations on small blood vessels of skin in the normal and in diabetic patients. Diabetes 15: 233-250

32. Vlassara H, Brownlee M, Cerami A (1986) Non-enzymatic glycosylation: role in pathogenesis of diabetic complications. Clin Chem 32 (10B): B37-B41

33. Tilton RG, Faller AM, Burkhardt JK, Hoffman PL, Kilo C, Williamson JR (1985) Pericyte degeneration and acellular capillaries are increased in the feet of human diabetic patients. Diabetologia 28: $895-900$

34. Timperley WR, Boulton AJM, Davies Jones GAB, Jarratt JA, Ward JD (1985) Small vessel disease in progressive diabetic neuropathy associated with good metabolic control. J Clin Pathol 38: $1030-1038$

35. Powell HC, Rosoff J, Myers RR (1985) Microangiopathy in human diabetic neuropathy. Acta Neuropathol (Berl) 68:295-305

36. Cunha-Vaz JG (1978) Pathophysiology of diabetic retinopathy. $\mathrm{Br}$ J Opthalmol 62: 351-355

37. Griffey RH, Eaton P, Sibbitt RR, Sibbitt WL, Bicknell JM (1988) Diabetic neuropathy: structural analysis of nerve hydration by magnetic resonance spectroscopy. JAMA 260: 2872-2878

38. Behse F, Bucthal F, Carlsen F (1977) Nerve biopsy and conduction studies in diabetic neuropathy. J Neurol Neurosurg Psychiatry $40: 1072-1079$

39. Folkman J (1985) Tumor angiogenesis. Adv Cancer Res 175-203

40. Kastrup J, Norgaard T, Parving HH, Lassen NA (1987) Decreased distensibility of resistance vessels of the skin in Type 1 (insulin-dependent) diabetic patients with microangiopathy. Clin Sci 72: 123-130

41. Rayman G, Williams SA, Spencer PD, Smale LH, Wise PH, Tooke JE (1986) Impaired microvascular hyperaemic response to minor skin trauma in type I diabetes. Br Med J 292: 1295-1298

42. Simpson LO (1988) Altered blood rheology in the pathogenesis of diabetic and other neuropathies. Muscle Nerve 2: 725-744

43. Guy RJC, Gilbey SG, Sheehy M, Asselman P, Watkins PJ (1988) Diabetic neuropathy in the upper limb and the effect of twelve months Sorbinil treatment. Diabetologia 31:214-220

Received: 16 October 1987

and in revised form: 28 December 1988

\section{Dr. A. K. Sharma}

Department of Anatomy

University of Aberdeen

Marischal College

Aberdeen AB9 1AS

UK 